\title{
GEOLOGICAL ASSOCIATION OF CANADA Newfoundland Section Annual Technical Meeting
}

\section{Abstracts \\ Applications of computers and geographic information systems (GIS) to the earth sciences}

\author{
Main Lecture Theatre \\ S.J. Carew Building \\ Memorial University of Newfoundland \\ St. John's, Newfoundland \\ February 23-24, 1995
}

This symposium is the Annual Technical Meeting of the Geological Association of Canada - Newfoundland Section. The symposium was sponsored by the Department of Earth Sciences, Memorial University of Newfoundland and the Geological Survey Division, Department of Natural Resources. 


\title{
Applications of GIS in water resources management
}

\author{
A. Beersing and $P$. Neary \\ Water Resources Division, Department of Environment, P.O. Box 8700, St. John's, Newfoundland AlB 4J6, Canada
}

In recent years there has been a paradigm shift toward dealing with development issues from an ecosystem planning perspective. An efficient and consistent data management system is essential to facilitate effective and meaningful evaluation of environmental impacts of proposed developments. The Water Resources Division is actively pursuing the implementation of GIS technology to assist in establishing and evaluating spatially oriented ecosystem-based decisions. This undertaking is being accomplished in three overlapping steps: development of a GIS database ranging from base topographic mapping, geology, hydrology, to environmental and cultural features; development of GIS functionalities to extract information from the database; and integration of GIS with environmental and hydrological models. The presentation will provide information on the progress of the development of the GIS database. The paper will also illustrate the GIS-related activities of the Division by means of several slides related to the calculations of watershed characteristics, land use changes over time, hydrology of Newfoundland, and interpretation of lake-water quality data.

\section{GIS in geology: overview and future trends}

\author{
G. Bonham-Carter \\ Geological Survey of Canada, 601 Booth Street, Ottawa, Ontario K1A 0E8, Canada
}

Geographic Information Systems (GIS) are computer systems for the capture, storage, manipulation, analysis, retrieval and display of spatial information. This talk examines the geological (as opposed to geographical) roots of GIS, as indicated by publications mostly in the field of computer geology. The present capabilities of GIS are reviewed, and some future trends are postulated.

From the moment commercially available mainframe computers appeared in the early 1960 s, computers began to be used for mapping applications in geology. Methods of trend surface analysis, automatic contouring, geostatistics and numerical modelling of fluid flow and sedimentation were published in the 1960 s, often with digital pen plotter output. During the 1970s, colour raster plotting of grid and vector data became popular, and digital databases of well logs and surface modelling software were widely used in the oil industry. The early 1980 s saw enormous changes due to computer graphics and PCs. The need to analyze satellite imagery catalyzed the development of raster image processing, and $\mathrm{CAD}$ systems made rapid advances for manipulation of vector data.

The modern commercial GIS, characterized by the graphical interface, the ability to handle both raster and topological vector data structures, with linkages to a relational database and ability to carry out map modelling operations, did not appear until the mid to late 1980 s. This brought about rapid changes in the practice of map production, field data capture, and the visualization and manipulation of map data of all types. Commercial 3-D GIS systems were developed mainly for use by the oil industry, who needed to manipulate and visualize sedimentary basin data, or deposit-scale models for use by the mining industry.

Future trends in GIS will improve the ability to (1) represent and analyze the effects of uncertainty in spatial data, (2) combine 2-d and 3-d functionality, as for example in merging seismic interpretations with geological constraints, (3) permit multiple data views to be manipulated dynamically, (4) automatically generate and track provenance information with each data layer, (5) provide much closer coupling of GIS to statistical and geostatistical analysis packages, and (6) apply new methods of analysis not restricted to traditional spatial statistics. It is to be hoped that improved standards for spatial data formats will be developed by international bodies, rather than by commercial GIS companies. Freedom of access to spatial data generated by government agencies is likely to be crippled by pricing policies in most countries except the United States. The movement of spatial data via the Internet will have a profound impact on the usage of data that is distributed at no cost.

\section{Computer-aided reclassification of the trilobite superfamilies Ptychopariacea, Conocoryphacea, Nepeacea, and Solenopleuridae......or blind trilobites could use come C.A.R.R.O.T.S.I \\ D. Boyce \\ Geological Survey Division, Department of Natural Resources, Government of Newfoundland and Labrador, P.O. Box 8700, St. John's, Newfoundland A1B 4J6, Canada}

Computer manipulation of digitized trilobite images indicates that the blind trilobite superfamily Conocoryphacea (Angelin, 1854) is polyphyletic, as many previous workers have suggested, and should be abandoned. Most taxa readily can be assigned to other superfamilies of the order Ptychopariida (Swinnerton, 1915). Of the genera included in the family Conocoryphidae (Angelin, 1854), Bailiella (Matthew, 1885), Conocoryphe (Hawle and Corda, 1847), and Parabailiella 
(Thoral, 1946) are assignable to the Ptychopariacea (Matthew, 1887). The distinctive Ctenocephalus (Hawle and Corda, 1847) and Elyx (Angelin, 1854) can easily be accommo- dated within the Nepeacea (Whitehouse, 1939). Finally, Bailiaspis (Resser, 1936) and Holocephalina (Salter, 1864) may be placed within the Solenopleuracea (Angelin, 1854).

\title{
Statistical regression models for predicting landslide hazard
}

\author{
C.F. Chung \\ Geological Survey of Canada, 601 Booth Street, Ottawa, Ontario K1A OE8, Canada
}

Based on several layers of spatial map patterns, regression methods have been developed for the construction of landslide hazard maps. The method proposed in this contribution assumes that future landslides can be predicted by the statistical relationships established between the past landslides and the spatial data set of map patterns. The application of regression techniques for delineating landslide hazard areas runs into two critical problems using GIS (geographic information systems): (i) the need to handle thematic data, and (ii) the sample unit for the observations. To overcome the first problem related to the thematic data, favourability function approaches or dummy variable techniques can be used. For the second problem related to the sample units, the unique condition subareas are defined where each subarea contains a unique combination of the map patterns.

Weighted least squares techniques are proposed for the zonation of landslide hazard using those unique condition subareas. The traditional pixel-based multivariate regression model becomes a special case of the proposed weighted regression model based on the unique condition subareas. This model can be directly applied to vector-based GIS data without the need of rasterization.

A case study from a region in central Colombia is used to illustrate the methodologies discussed in this paper. To evaluate the results adequately, it was pretended that the time of the study was the year 1960 and that all the spatial data available in 1960 were compiled including the distribution of the past landslides occurred prior to that year. The statistical analyses performed are based on these pre-1960 data about rapid debris avalanches. The prediction was then compared with the distribution of the landslides which occurred during the period 1960 to 1980.

\section{Quantitative techniques for geological mapping using geophysical data}

\author{
C.F. Chung \\ Geological Survey of Canada, 601 Booth Street, Ottawa, Ontario KIA OE8, Canada
}

A research project has been initiated to use geophysical data to delineate geological patterns as an aid to geological field mapping in Arctic regions in Canada. The Hall Lake area in Melville peninsula, Northwest Territories, has been chosen for this study, because the area has little vegetation, relatively large areas of unweathered rock outcrop and a geological map covering a part of the area has been recently published.

A subarea of $15 \mathrm{~km} \mathrm{x} 15 \mathrm{~km}$ which consists of $512 \times$ $512(=262,144)$ pixels of the size of $30 \mathrm{~m} \times 30 \mathrm{~m}$, were selected as a test area. Among the 262,144 pixels, two sets of training samples, the first set consists of 144 pixels sys- tematically selected; and the second set consists of 153 pixels where the field stations were located for the geological mapping, were chosen to test the technique.

Neural network algorithm and Logistic discriminant analysis were applied to each one of the two sets as a training, then the classification results were then used to predict the geological units in the remaining test area. In this test area, both neural network procedure and logistic discriminant models have adequately characterized the geological units from the geophysical data within each training area, and accurately (over $90 \%$ ) predicted the geological units in the entire area.

\section{GIS and digital mapping in the Newfoundland geological survey}

\author{
P. Davenport, L. Nolan, G. Kilfoil and P. Honarvar \\ Geological Survey Division, Department of Natural Resources, Government of Newfoundland and Labrador, \\ P.O. Box 8700, St. John's, Newfoundland A1B 4J6, Canada
}

Geoscientific information can be a major instrument for promoting sustainable economic development. The geoscientific database for Newfoundland and Labrador has grown rapidly in both volume and scope over the past 20 years, and is playing an increasingly important role in mineral, hydrocarbon and infrastructure development in this province. To be used to full effect, this information must be readily available to both traditional users and to new user-groups. Informa- tion technology has opened up a plethora of new ways to distribute geoscientific information. To maintain a competitive edge, it is necessary not only to maintain an up-to-date database, but also to distribute it via these new techniques. This requires the translation of the database to a digital format.

Several separate datasets have been available digitally for some time, e.g., regional geophysical and geochemical 
data, and mineral occurrence data. More recently desk-top mapping systems, such as ArcView, have been employed to present digital atlases of geochemical, geophysical and related geological and topographic information. These atlases contain both data and interpreted themes for use by both specialist and non-specialist. Themes and databases from individual atlases are easily linked to each other and to digital indexes containing the areal coverage of surveys and reports and bibliographic information from GEOSCAN. An atlas of construction aggregate resources is being compiled currently.

These linkable atlases become increasingly useful as more themes of geological, topographic and land-use data are added.
In principle, virtually all of the Survey's information could be disseminated through desk-top mapping systems. Rather than the ad hoc software used to date to prepare the atlases, much of this work will in future be accomplished using the CARIS GIS. Pilot projects to compile comprehensive databases of geoscientific data and information from government, mineral industry and academic sources are being carried out for the Buchans-Roberts Arm belt, Newfoundland, and the Kanairiktok project area in Labrador. CARIS is the main tool for this work, and will likely be used for the organization, storage, retrieval and in-house analysis of the Geological Survey's geoscientific database.

\title{
Construction of geological databases from regional surveys
}

\author{
J.P. Hayes \\ Geological Survey Division, Department of Natural Resources, Government of Newfoundland and Labrador, \\ P.O. Box 8700, St. John's, Newfoundland A1B 4J6, Canada
}

Regional geological bedrock mapping involves airphoto reconnaissance, ground and helicopter traverses followed by office and laboratory investigation of field samples. The data obtained through these studies are reported in a series of printed maps and reports. A significant portion of the information that a geological map contains is actually an interpretation of the data collected during mapping. Much of the original data is not immediately available to map users. With increasingly powerful computers and improvements in database and mapping software it is now possible to construct detailed digital databases from the original field observations. These technological improvements can provide map users with a means to access the original mapping data and to process and exchange mapping data in digital format.

Digital databases of geological information originating from projects which capture data in a digital format are likely to be more comprehensive than those digitized after collec- tion. However, much of Newfoundland is already mapped and significant amounts of primary mapping data reside in project archives. A process has been initiated to make these data available in digital format. Together with digitized versions of published geological maps these represent an important information resource.

When complete, each mapping archive will consist of digitized geological maps, traverse and sample location maps. These will be complemented with a database of outcrop and sample descriptions, structural and analytical data. Basic geological information such as rocktype identification and brief description together with comprehensive records of structural information can be extracted from most notebook entries. Application of GIS technology permits the linking of site information in the database with the published map. At this stage it is possible to conduct further analysis of the mapping data in conjunction with other mapping or thematic geological databases.

\section{The digital index concept of accessing information from geophysical survey databases}

\author{
G.J. Kilfoil \\ Geological Survey Division, Department of Natural Resources, Government of Newfoundland and Labrador, \\ P.O. Box 8700, St. John's, Newfoundland AlB 4J6, Canada
}

As part of the Geological Survey's mandate, geophysical data collected within the province are being processed to a more useable form and archived for ready access by user groups (mining industry, government and university). The two main sources of this data are systematic regional government-sponsored surveys collected to enhance mineral exploration activities within the province and industry-sponsored surveys designed to investigate specific mineral properties. These surveys vary widely in area covered, detail geophysical parameters measured, from potential fields to electromagnetic and induced polarization responses, or combinations of these. This diversity has implications for the design of the digital database used to store the results. A further complication arises in that older data were collected by analog means and interpreted, or interpolated products were submitted in analog form with assessment reports.

From the data management perspective, the shear volume of geophysical information requires a means by which data from various sources may be efficiently catalogued and accessed. As well, if analog datasets are to be converted to digital for inclusion in a structured database, the first logical step is to determine the magnitude of the task by compiling a digital catalogue and then to prioritize certain surveys on such criteria as data quality and assessed need.

The digital index concept is created by attaching some 
georeferencing information to the geophysical survey catalogue so that standard library searches can be restricted spatially. When properly constructed, a visually-oriented digital index can serve many purposes. For those involved in assembling databases, a digital index can be a tool for both project planning and for the management of quite diverse databases. For the user groups, a digital index can be quickly searched to determine the level of information available for an area of interest and can also provide a means of efficiently navigating through a maze of compiled databases.

Following initial attempts using other software packages, ArcView was adapted as an effective tool to query and display information from digital indexes of airborne geophysical surveys conducted within the province. Several features of ArcView are particularly suited to this task:

(a) all geographic entities (points, lines and polygons) are coregistered;

(b) each entity is directly linked to a database file record and these records can be easily altered or updated; (c) information contained in each field can be selectively queried to limit a search and to classify the data;

(d) thereby changing the characteristics of an image or map; and

(e) ArcView operates on several computer platforms within the Windows GUI which provides an intuitive environment for the user.

Two digital indices in ArcView have been built for geophysical surveys, one for insular Newfoundland and one for Labrador. As airborne surveys often overlap, the descriptive information for these indexes has been associated with a line coverage, which is comprised of polygonal extents of each survey. Similar province-wide digital indexes are currently being constructed for ground-based geophysical surveys. Digital indexes have also been constructed for regional and detailed geochemical surveys in Labrador and for systematic bedrock mapping in Newfoundland.

\title{
Development and use of the shotpoint location system in the Newfoundland offshore area
}

\author{
J. McIntyre and W. Dohey \\ Canada-Newfoundland Offshore Petroleum Board, 140 Water Street, St. John's, Newfoundland A1C 6H6, Canada
}

The Canada-Newfoundland Offshore Petroleum Board is the joint federal/provincial authority responsible for the administration of regulations pertaining to all exploration for and production of hydrocarbons in the Newfoundland offshore area. Over 300 geophysical seismic programs have been recorded offshore since exploration began in 1964, with more than 500,000 line $\mathrm{km}$ of 2-D and 3-D seismic data acquired. The Shotpoint Location System was developed jointly with the Canada Oil and Gas Lands Administration to allow effective management of this large amount of data. Shotpoint location and statistical information is stored in an Oracle database and accessed through customised screens and routines. Output is in report and/or map format and may include locations of seismic lines, wells, land and feature information. The application is used to provide information for both in-house and external data requests.

\section{Mineral exploration targeting using AutoCAD as a geographic information system}

\author{
S. McLaren and P. Tallman \\ Black Pine Limited, P.O. Box 216, Station C, St. John's, Newfoundland AIC 5J2, Canada
}

Most exploration companies already use AutoCAD as part of their mineral exploration activities for drafting maps and diagrams. Apart from a technical drafting tool, AutoCAD has a wide range of advanced GIS-like capabilities which are rarely used.

Black Pine applies AutoCAD as a geographic information system in creating mineral exploration compilations. AutoCAD offers a practical method of compiling geological information and is fully compatible with other GIS software through AutoCAD's DXF drawing interchange format.

There are four stages in generating a mineral exploration compilation in AutoCAD:

(1) Data Collection: Primary sources of information are obtained from the user in the field and from government. Data types are defined as either graphical or numerical and text. Graphical data, such as topography or geology maps, and numerical and text information such as assays or lake sediment UTM coordinates, may be in a variety of formats including on paper, in digital files (vector or raster), and in spreadsheet or text (ASCII) files.

(2) Data Entry: All data must be entered into AutoCAD and referenced by a common coordinate system, such as a UTM grid. Graphical data can be input by manual digitizing or optical scanning. Numerical and text data are input by creating digital spreadsheet files and saving them in ASCII format. Data can then be entered automatically using AutoLisp - AutoCAD's programming language. Different data sets are placed on separate layers in the AutoCAD drawing file so that the compilation can be manipulated to suit the user.

(3) Data Interpretation (Exploration Targeting): The geological compilation can be visually interpreted using "overlays" of data layers from the AutoCAD file. These can be viewed on the computer monitor or plotted on paper or mylar for analysis. AutoCAD also has a SQL or Structured Query Language extension which can be 
used to ask questions about the compilation. For example, the question "What lake sediment anomalies (> $5 \mathrm{ppb} \mathrm{Au}$ ) overlie conductors or magnetic highs?" can be asked of the compilation. AutoCAD highlights all the applicable lake sediment samples on the screen and these can be plotted or printed as required.

(4) Data Presentation: Specific layers in the AutoCAD compilation can be selected and plotted for presentation. Layers can also be extracted and exported into other graphics software, such as CorelDraw. CorelDraw can be used to generate a suite of promotional products such as brochures, press releases, poster displays, slides, transparencies and diagrams for reports, all in full colour.

Small exploration companies rarely have the budget or time to install a GIS for use in mineral exploration. AutoCAD provides an accessible, relatively cheap way of creating digital databases for use in exploration programs - and creates a base from which presentation products can also be made.

\title{
The GIS program in the Department of Geography, Memorial University of Newfoundland
}

\author{
A. Simms \\ Department of Geography, GEOIDAL Group, Memorial University of Newfoundland, \\ St. John's, Newfoundland AlB 3X5, Canada
}

The Department of Geography at Memorial University offers a program in GIS and remote sensing. This paper presents a summary of the program and introduces the Geo-

graphical Information and Digital Analysis Laboratory (GEOIDAL) located at the Department of Geography.

\section{Peatland management and decision making using geographic information systems}

\author{
A. Simms \\ Department of Geography, GEOIDAL Group, Memorial University of Newfoundland, \\ St. John's, Newfoundland AIB 3X5, Canada
}

The utilization of a geographic information system (GIS) for peatland management requires the development of spatial databases at various resolutions. Spatial database requirements are dependent on the level of planning required. The four planning levels presented are: (1) strategic plan- ning, (2) tactical planning, (3) operational planning, and (4) project planning. This paper presents a framework for the development of spatial databases for peatland assessment and management.

\section{A geographical information system approach to geotechnical data}

\section{St. Croix}

Geological Survey Division, Department of Natural Resources, Government of Newfoundland and Labrador, P.O. Box 8700, St. John's, Newfoundland AIB 4J6, Canada

The Geological Survey Branch of the Department of Natural Resources has been collecting data on the quality and distribution of the province's aggregate resources for about twenty years. Over this time frame the methods used to store and manage this data have undergone several transformations as the volume of data increased and technologies improved.

The current system involves several PC databases and associated maps prepared separately by the responsible groups.
The lack of a graphical interface and the limitations of accessibility and data presentation leads to a time consuming and repetitive exercise when handing the user groups requests. We see the development of a geographical information system as a productive step in addressing the needs of our user groups and for managing the ever increasing volume of data.

\section{Linking geological, soil and vegetation data using GIS to predict early tree growth in central Newfoundland}

\author{
B.D. Titus ${ }^{1}$, S. Yamasaki ${ }^{2}$ and J. Fyles ${ }^{2}$

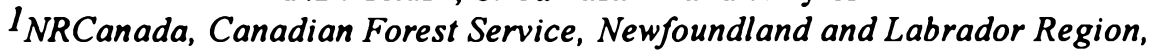 \\ P.O. Box 6208, St. John's, Newfoundland AIC 5X8, Canada

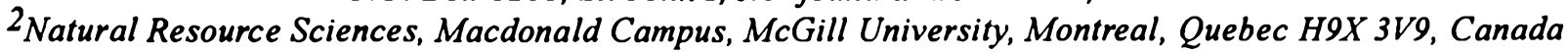

\footnotetext{
"Wood supply" models are used to calculate "annual allowable cut" in a manner analogous to using fish population models to determine "total allowable catch". The assumptions on which early (0-20 years) plantation growth
}

rates are based are still simplistic and require further refinement. In particular, most plantations are located in central Newfoundland where the presence of an ericaceous shrub, Kalmia angustifolia, can severely reduce the early growth 
of planted black spruce seedlings. An ideal seedling growth model would predict seedling performance based upon innate site productivity, successional status, the amount of $\mathrm{Kalmia}$ present and its rate of spread.

To build towards this, the positions of approximately 6000 seedling assessment quadrants on 1:12,500 map sheets from a 1992-93 provincial plantation survey in central Newfoundland were located and digitized. Attribute tables were then generated for each of these points from GIS maps of bedrock and surficial geology, forest capability (CLI), dominant and sub-dominant soil attributes, and forest inventory cover type. Analysis is on-going, but it is hoped that a first approximation of a field manual can be tested in 1995, which will allow for prediction of spruce performance based upon GIS-generated information on geology, site and soils, and simple field measurements of biological features. If the predictive capabilities can be refined and are accurate enough, then the potential exists to move to an area-based model that can be linked directly into forest management GIS maps and even satellite images of Kalmia distribution for prioritizing silvicultural decisions and improving the accuracy of wood supply models.

\title{
Earth sciences GIS at the university level; opportunities for teaching, research and development
}

\author{
H.W. van de Poll ${ }^{1}$ and R.W.W. van de Poll ${ }^{2}$ \\ ${ }^{1}$ Department of Geology, University of New Brunswick, Fredericton, New Brunswick E3B 5A3, Canada \\ 2 Universal Systems Limited, Fredericton, New Brunswick, Canada
}

Computers are playing an increasingly important role in earth science studies and mineral exploration. PC-based software, dedicated to accomplish specific geological or geophysical tasks has been around for several decades. Lately, however, interests have started to include GIS software because of its locational accuracy, ability to accommodate large multi-source datasets and its integrational, analytical and modelling capabilities. These are software characteristics of particular interest to mineral explorationists because the present techniques of hard-copy data integration are very time-consuming.

The GIS Laboratory of the Department of Geology, University of New Brunswick, has been active in developing geology related software applications using CARIS (Computer Aided Resources Information System).

Past and present projects include:

(1) Geological mapping software-applications for UNIX and
MS Windows platforms as well as a pen-operated computer;

(2) Environmental-protection software applications centred on watershed and groundwater studies and waste-storage site selection; and

(3) Introducing computer-based geological mapping at the undergraduate student level and as professional retraining by means of conventional classroom as well as Distance Education teaching techniques.

As the earth sciences gradually expand into the GIS environment the demand on the universities to become more extensively involved in teaching GIS related subjects will be increasing. Considering the rate at which computerization of the workplace is expanding in general, one can anticipate that within a decade geology graduates will be expected to be able to work in fully integrated electronic environments.

\section{CARIS GIS, a mineral exploration information system (MEIS) geocompilation project for the Big Bald Mountain region, NTS sheet 21/01 New Brunswick}

\author{
R.W.W. van de Poll ${ }^{1}$ and H.W. van de Poll ${ }^{2}$ \\ ${ }^{1}$ Universal Systems Limited, Fredericton, New Brunswick

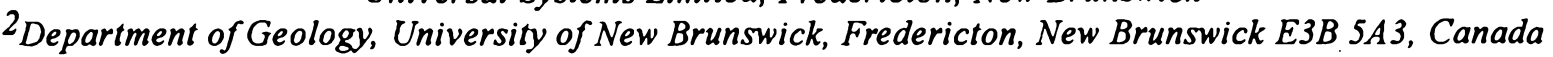

Geological maps and Provincial Mineral assessment data are currently being converted into CARIS (Computer Aided Resource Information System) digital format by the New Brunswick Department of Natural Resources, Mines Division. To Date about $1 / 4$ to $1 / 3$ of the data for the province is available at $1: 10,000$ and $1: 20,000$ scale map.

A joint project between members of Universal System Limited, the GIS Laboratory of the Department of Geology at UNB, and the Department of Natural Resources, Mines Division, is currently in process compiling all public available geological data for NTS maps sheets 21/01, Big Bald Mountain Region of New Brunswick. The source data in- cludes all current assessment information on file from the Department of Natural Resources, Mines Division, all available geophysical data from the Geological Survey of Canada, specifically both the Geophysical Division, and the Gamma Ray Division, and all open files from Provincial/Federal funded mapping projects from the Department of Natural Resources.

The CARIS MEIS (Mineral Exploration Information System) is a GIS tool that allows the user to manage, integrate and analyze various types of stored Earth Science data to assist the geologist in the decision-making process for future exploration programs. A cross section of data and data integration will be given in this presentation. 